\title{
La virtud de la justicia en directivos según Leonardo Polo
}

\author{
Genara Castillo \\ Universidad de Piura
}

\section{Introducción}

Si bien se suele tratar más de la prudencia que de la justicia, ya que sin ella se cometen errores que tienen un costo muy alto. Según Leonardo Polo «la virtud ética primaria es la prudencia. La prudencia es una virtud dianoética; es decir, una virtud intelectual que marca el enlace de la inteligencia con la conducta práctica, en tanto que la conducta práctica puede y debe ser dirigida. La prudencia es un tema ético central en la tradición occidental. Actualmente ella está desacreditada o más bien descuidada. Aunque es evidente que cualquier hombre de acción la está utilizando constantemente: está viviendo la prudencia en el manejo de sus asuntos; de lo contrario no puede subsistir» (1997, p. 51).

Sin embargo, todas las virtudes están conectadas, justamente parte de la deliberación que exige la prudencia involucra a la justicia ya que si bien la deliberación está centrada en los medios ello incluye a las personas y a los bienes a los cuales ella tiene derecho. En este sentido es muy significativo que la justicia sea considerada virtud social básica, y ya que ha sido tratada por muchos autores nos centraremos en este artículo en el aporte que da al tema el filósofo Leonardo Polo.

\section{Sobre la virtud de la justicia}

Según Leonardo Polo se entiende la justicia «como la voluntad firmemente dispuesta a dar a cada uno lo suyo, y actuar en consecuencia. La conciencia moral, que es uno de los asientos de la ética en el ser humano, dictamina que es mejor la justicia que la injusticia. Pero, por otra parte, también es verdad que el hombre actúa frecuentemente de manera contraria. Para dar a cada uno lo suyo es menester que lo del otro sea tan importante como lo propio (lo mío). Pero el hombre de entrada da más importancia a lo propio que a lo del otro» (1993, pp. 81-82). 
La virtud de la justicia nos ayuda a adherirnos a los bienes a los que el otro tiene derecho, y por eso es tan necesaria porque de entrada no somos justos, es decir que buscamos más el bien propio que el ajeno y es la justicia la que ayuda a la voluntad a querer el bien de los demás. Por ello, a diferencia de la prudencia, la justicia no es considerada virtud dianoética, sino que su asiento es propiamente la voluntad cuyo acto es el querer los bienes presentados por la inteligencia, pero que es la voluntad la que se adhiere o no a esos bienes, por ello, en los actos de justicia el fiel de la balanza se inclina hacia la voluntad, que es la que libremente puede adherirse o no a ellos.

En este sentido, teniendo en cuenta que el ámbito propio de la justicia es la voluntad, nos podemos preguntar cómo se da el despliegue de la voluntad, que tradicionalmente se le ha considerado una tendencia racional. Para ello partimos de que el acto propio de la voluntad es el querer bienes, pero a diferencia de las tendencias sensibles que se adhieren a bienes captados por los sentidos, la voluntad crece cuando se adhiere a bienes que la inteligencia le presenta; así, por ejemplo, un ser humano puede querer que le realicen una operación quirúrgica para extirparle unos tejidos cancerígenos, aunque la tendencia sensible le repugne y sienta aversión al hecho de que le tengan que intervenir realizándole algunos cortes en su cuerpo: los quiere con su voluntad pero no los desea con su tendencia sensible.

¿Qué nos indica esto? ¿Qué secreto guarda la voluntad? Es importante tratar de esclarecerlo porque si algo necesita una persona $-\mathrm{y}$ especialmente un directivo - es una voluntad vigorosa capaz de sostener y llevar adelante proyectos o empresas de gran envergadura. A continuación, trataremos de reflexionar sobre lo que sucede con el querer de la voluntad cuando se ejercita la justicia.

Una pista la da la otra gran virtud «social»: la amistad. Para Polo hay una jerarquía en las virtudes y la amistad es la virtud culminar, que da al otro no lo «suyo» sino de lo «mío», por lo que está por encima de la justicia, aunque como ya hemos señalado todas las virtudes están conectadas y es claro que no habría virtud de la amistad si se es injusto con el amigo. Entonces podemos profundizar más y ver por qué estas virtudes fortalecen tanto a la voluntad, empezando por la justicia. Ya hemos advertido que tanto la justicia como la amistad nos ponen delante al otro, por lo que llevan a vivir la alteridad (alter=otro), de manera intensa.

¿Cómo sucede esto? Como es sabido, la voluntad crece proporcionalmente al nivel de bienes a los que se adhiere. Con la justicia la voluntad puede vivir la alteridad de manera intensa porque al querer al otro tenemos que este no es una cosa, no es un bien medial, no es un objeto cualquiera, sino que es una persona que es un bien que posee una entidad mayor que la de los bienes mediales, por eso la voluntad crece al adherirse a esos bienes de gran entidad como son los seres humanos. 
$\mathrm{Al}$ respecto, Polo afirma que para ser justo se precisa de que lo del otro sea tan importante que lo propio, lo cual exige a la voluntad ser capaz de querer el bien por ser tal, independientemente de que sea mío; es decir, que la voluntad le lleve a querer aquello para lo cual está hecha y que es el bien, y que tenga la fuerza suficiente para que pueda descentrarse y abrirse a unos bienes que no por ser ajenos dejan de ser bienes, lógicamente la cantidad de bienes que son ajenos es mucho mayor que los propios. Y, además, como esos bienes pertenecen a otro se requiere que la voluntad se adhiera al otro como bien y siendo este un bien final ${ }^{1}$, es decir, su entidad es mucho mayor que las cosas, que son bienes mediales, entonces esa voluntad crece muchísimo.

Tenemos entonces que para ser justos (como para vivir bien la amistad) se requieren voluntades vigorosas, porque espontáneamente no somos justos (Polo, 1993, p. 82 y p. 115), sino que estamos inclinados a buscar lo propio, por tanto se requiere un gran esfuerzo para poner por encima o delante el bien ajeno y controlar la inclinación a lo propio a costa de lo ajeno. Es claro, entonces, que si no se practica esta virtud podemos arrasar con los bienes ajenos y con el otro como bien, pero entonces la voluntad se debilita, «se hace pequeña».

A este respecto es relevante que un auténtico empresario se caracterice por su magnanimidad, quiera lo grande, anhele hacer cosas buenas, por su país, por los demás. Ese vigoroso querer de su voluntad no es algo que se improvisa, conlleva mucho ejercicio de un querer mucho y bien, en lo grande y en lo pequeño.

¿Cómo se puede practicar la justicia? Lo primero es recordar que hay que partir del hábito innato de la sindéresis, que es una luz por la que nos damos cuenta de que somos seres humanos racionales y que por tanto tenemos que buscar la verdad y el bien coherentemente. Según Tomás de Aquino esa luz de la sindéresis no la perdemos nunca, aunque estuviera muy agostada, no desaparece porque entonces dejaríamos de ser humanos.

Es gracias a la sindéresis que nos damos cuenta de que somos seres humanos y que por tanto tenemos que conducirnos como tales, de ahí que la ley que naturalmente se desprende de esa luz es: ¡Haz el bien! ¡Crece! Lo que sucede es que paulatinamente hemos ido reduciendo ese principio y hemos sustituido el ¡haz el bien! con el «evita el mal», pero esto es una de las consecuencias, no es lo principal: el mandato es de crecer en el bien. Las normas en sentido negativo - precedidas del «no» - son una advertencia: solo señalan la delgada línea roja que no hay que cruzar, debajo de lo cual nos deterioramos, pero el sentido de la norma es el crecer.

1 Es evidente que la entidad de un ser humano es mayor que la de las cosas, de ahí que haya que considerarle fin y no medio, que es de inferior categoría porque las cosas que son medios no se quieren por sí mismas, sino por un fin diferente de ellas. En cambio, las personas no pueden ser tratadas como medios porque no son cosas, su entidad y riqueza ontológica es mayor que lo medial, y hay que tratarles como fines y no como medios. 
Ese rebajamiento es lo que ha llevado a la llamada ética de mínimos, que está muy lejos de la ética aristotélica y poliana, y que lleva a algunas personas a considerar que son buenas porque «no roban» $\mathrm{o}$ «no matan»; siendo que el gran reto es el crecimiento y el aporte tanto a nivel personal como organizacional. Como afirma Polo:

Ser ético es ser más, y eso en el tiempo significa también tender a más. Un hombre moderado, cauteloso, que no roba, que no hace daño..., no es un ser ético, jes un asténico, está parado! Nunca somos suficientemente éticos. ¿Somos justos? De entrada, no lo somos, porque para ser justo es menester ser sumamente ambicioso (1993, p. 115).

Es la sindéresis la que espolea la realización de la justicia, ya que esa luz por la que somos conscientes - vemos - nuestro yo, nuestra condición humana y nos damos cuenta de que estamos llamados a querer y a querer-querer, ese crecer que avizoramos es un gran acicate. De ahí que según Polo existe una conexión entre las virtudes que se convierten en cuanto las inferiores son elevadas de acuerdo ese querer más y mejor, según la alteridad:

Los actos voluntarios se distinguen estrictamente por la intensidad de la intención de otro, la cual es creciente, porque dichos actos son constituidos por la sindéresis. Teniendo en cuenta que las virtudes morales están estrechamente imbricadas con los actos voluntarios, se ha de sostener que el crecimiento de las virtudes explica tanto su distinción como su carácter sistémico. Con otras palabras, una virtud se «convierte» en otra atendiendo a la intensificación de la intención de otro de los actos voluntarios con los que se adquiere. Según este criterio, la prudencia se convierte en justicia, y la justicia en amistad. Por eso, en vez de hablar de partes potenciales de cada virtud, es preferible admitir que las virtudes inferiores son elevadas de acuerdo con lo que llamo su «conversión». De acuerdo con esto, la justicia es prudente, y la amistad es prudente y justa, pero no al revés: por ejemplo, antes de su elevación, la prudencia no es justa (2003, p. 180).

En esa línea está la consideración de que la justicia es superior a la prudencia: «la virtud de la prudencia se adquiere con la pluralidad de los actos electivos, y culmina con lo que se llama imperio, que marca el paso de la elección a la acción. A su vez, si las acciones no se detienen en la obra, se adquiere la virtud de la justicia» (Polo, 2003, 169). Es decir que en la justicia la acción humana no se detiene en la obra, sino que la atraviesa prolongando su «intención de otro», el querer de la voluntad va más allá de los medios.

Con todo, cabe insistir: ¿qué significa que se «eleve» el querer de la voluntad en el plano de la virtud ética? Significa que nuestra voluntad está naturalmente dirigida a querer el bien, pero no lo está de manera natural inclinada a querer el bien ajeno, por eso se requiere ese «refuerzo» de la sindéresis, para espolear a la voluntad a tender a otro y por eso mismo es que tratar de vivir la virtud de la justicia es indispensable:

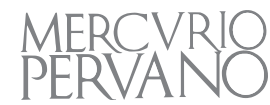


La justicia es un hábito imprescindible porque la voluntad humana tiende naturalmente al bien, pero no tiende naturalmente al bien de los demás. Ese bien excede la capacidad volitiva, ya que cada uno apetece su propio bien. Dicho de otra manera, la justicia y la inclinación a la felicidad son divergentes, de manera que, sin una virtud sobreañadida la voluntad no podría llevar a cabo actos justos. Por tanto, aunque la justicia sea una virtud de la voluntad, no se puede explicar desde ella, ya que excede su inclinación natural. De aquí que sea precisa la ayuda de la ley natural, para que la voluntad pueda tender, según esta virtud, a bienes que son externos a su inclinación natural. La ley natural se suele describir como la participación en el hombre de la ley eterna de Dios (Cfr. Suma Teológica, I-II, q. 91, a. 2c). De acuerdo con lo dicho, la ley natural no pertenece a la voluntad, sino a la razón, y se aplica a las virtudes ordenándolas a su fin. El bien al que la justicia inclina es siempre el que es debido a otros hombres (Polo, 2003, p. 180).

Antes de pasar al siguiente apartado, es oportuno recordar la importancia de la virtud, de la justicia y de todas las virtudes morales ya que el fortalecimiento de la voluntad está relacionado con la felicidad humana y con el amor:

La ética no es unilateralmente la ciencia del bien; tampoco es sólo ética de normas o meramente instrumental; la ética también se ocupa del amor, es decir, de la adhesión al bien «que no falte el bien y que yo no le falte al bien». Pero si es preciso no faltarle al bien, el cumplimiento de las normas no puede ser puramente fastidioso, como si fueran producto de una voluntad arbitraria. Las normas ellas mismas también son amables, y así lo dice Tomás de Aquino (Suma Teológica, 1-2, 107, 4 ad 2m et 3m); pero esto sólo se sabe cuando se tienen virtudes (Polo, 1997, p. 116).

Y en esa línea las virtudes hacen al ser humano libre: La voluntad se hace libre gracias a los hábitos:

La voluntad es voluntad de un quien en cuanto que es libre. Pero la voluntad es libre sólo porque adquiere hábitos; si no, la libertad, que es radicalmente personal, no la inviste, no llega a ella. La estructura, como se ve, es compleja. Pero no conviene olvidar que la riqueza ontológica de la voluntad procede de su entronque en el ser personal. En los manuales de ética clásica (otras interpretaciones de la ética son reduccionistas) estas cuestiones no están suficientemente desarrolladas o se resuelven de una manera demasiado rápida. Sin embargo, estas distinciones son muy importantes porque explican cosas que de otro modo no se entienden. Según el concepto de sistema libre, mencionado en los capítulos anteriores, entran en juego muchos elementos: la naturaleza, los bienes, los actos, los hábitos, la libertad, la persona, la inteligencia, la voluntad, que la filosofía debe estudiar (Polo, 1997, pp. 153-154).

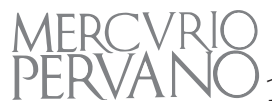




\section{La formación de la justicia en el directivo}

Luego de lo expuesto, podríamos preguntarnos sobre cómo se puede aplicar lo anterior a la dirección de empresas u organizaciones, cómo ayudar a los directivos a vivir la justicia y a vencer la inclinación de ir solo a lo propio dándoles las espaldas a los otros y a lo que les corresponde.

Como hemos visto se trata de ayudarlos a elevar su querer, esto es lo que en una escuela de dirección se trata con el gran tema de las «motivaciones» humanas, que dicho de manera rápida pueden ser de tres niveles (Cfr. Pérez López, 1996):

a. Motivaciones extrínsecas: bienes materiales, reconocimientos externos, etc.

b. Motivaciones intrínsecas: aprendizaje, incremento de conocimientos.

c. Motivaciones trascendentes: interesarse por ayudar a los demás, hacerse cargo de sus necesidades reales, etc.

Evidentemente, el ser humano, y el empresario de manera especial, necesita de bienes del primer nivel: extrínsecos, de dinero, de bienes materiales, etc. Pero para ayudarles a hacer justicia con las cosas, deben aprender cómo ponerlas en su lugar, reconociendo su condición de medios relacionándolos con fines de mucho nivel como son los intrínsecos (conocimiento) y, especialmente, con los trascendentes.

Y para poder usar bien las cosas hay que reflexionar acerca de su uso, darles el tiempo que necesitan estos asuntos, ni mucho ni escaso, sino el suficiente para no precipitarse e incurrir en el error:

en toda injusticia hay un error de fondo; el hombre comete faltas morales porque yerra; además, el error tiene razón de pecado porque es consecuencia de la precipitación que lleva a afirmar lo que se ignora, lo cual es un pecado contra el pensamiento y contra la verdad. Para evitar el error hay que reconocer la complejidad de los asuntos. Demorarse en el análisis social es buscar la verdad de la situación. Sólo si se acierta, cabe aspirar a mejorar la situación (Polo, 2010, p. 216).

En ese sentido para un directivo ser justos es practicar la deliberación requerida por los asuntos que conciernen a su organización y a sus decisiones, tratando de incrementar la verdad y evitar el error, fomentando la virtud de la veracidad, la sinceridad, ya que todos tienen derecho a la verdad, por lo que existe el deber de poner los medios para obtener esa verdad y expresarla de la manera más adecuada.

Especialmente es preciso que el directivo exija a sus colaboradores fomentar entre todos el respeto que se manifiesta no solo en la afabilidad y el buen

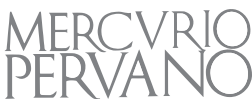


trato «formal», sino que traten de tomar en serio sus aportes, de escucharles y hacerles partícipes de información pertinente, de aportar sus puntos de vistas respecto de determinados asuntos, etc., a su nivel, pero valorándolos, sin menospreciarles por ser personas con pocos bienes materiales o incluso de pocos conocimientos debidos a una precaria educación, porque por encima de su tener está la dignidad y riqueza de su ser personal, que hay que reconocer, valorando su existencia como un don.

Algo importante que se debe añadir es que el directivo no solo tendría que tratar de ser justos con sus trabajadores, sino no impedir que ellos sean justos. Por ejemplo, no les debe pedir que hagan cosas injustas, partiendo de su ámbito más próximo como es el familiar, tratando de que no atropellen sus deberes familiares con horarios no aptos para una persona casada y con hijos que atender.

En general es importante que los directivos aprendan a vivir la llamada justicia conmutativa, que regula los intercambios entre particulares y la justicia distributiva que distribuye cargos y beneficios de acuerdo con aptitudes y con méritos respectivamente. Respecto a la primera es importante que revisen cuidadosamente su política de incentivos, los salarios, etc. Y en lo que se refiere a la distributiva, el ser justos en las promociones para que prime la meritocracia $\mathrm{y}$, en el reparto de beneficios para que no triunfe el amiguismo o favoritismo.

Además, algo importante para vivir la justicia en las organizaciones es respetar el derecho a la buena fama que tienen todos los seres humanos, por tanto, no permitir la murmuración, menos la calumnia, porque la justicia requiere dar a cada uno lo suyo, pero también no quitarle lo que tiene. Y si una persona tiene derecho al buen nombre y se habla mal de ella, se inclina a los demás a que le retiren el aprecio y no se relacionen con esa persona de la manera más adecuada, lo cual no es justo.

En sentido positivo se trata de vivir con los demás la lealtad que es la virtud que reconoce los vínculos libremente adquiridos, reafirmándolos, y no destruyéndolos. De ahí que hablar mal de los compañeros o de la propia empresa es una deslealtad que afecta a la justicia. Sin embargo, también la virtud de la justicia lleva a tratar de ayudar a quien yerra, buscando la manera de que si un compañero obra mal se le pueda advertir a tiempo y del mejor modo respecto de su mala acción o mal hábito para que se corrija.

En suma, un directivo actúa con justicia cuando ayuda a los demás a crecer por medio de su trabajo, ya que una manera de ser justos es aportando a la sociedad el trabajo bien hecho, prestando un servicio de calidad o produciendo de tal manera que todos los involucrados se exijan creciendo como seres humanos. Como afirma Polo «el que ama la justicia está impelido a ayudar a los demás» (2014, p. 302) para que se pongan en condiciones de ser perfeccionadores perfectibles, que mejoren a los demás, mejorándose ellos en primer lugar. Con todo, existen casos muy difíciles de vivir la justicia, ya que superan la capacidad humana de satisfacer el deber de dar lo que en esos casos corresponde y que

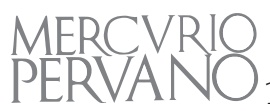


tienen que ver con las virtudes de la piedad, respecto de los padres y de Dios con quienes tenemos una deuda impagable, que es muy difícil de satisfacer del todo, y que por lo menos se trata de cumplir viviendo la virtud de la piedad y de la gratitud.

\section{Referencias bibliográficas}

Pérez López, J. A. (1996). Fundamentos de la dirección de empresas. Madrid: Rialp.

Polo, L. (1993). Quién es el hombre. Un espíritu en el tiempo. Piura: Universidad de Piura.

Polo, L. (1997). Ética. Hacia una versión moderna de los temas clásicos. Madrid: Unión Editorial.

Polo, L. (2003). Antropología trascendental, II. Pamplona: Eunsa.

Polo, L. (2010). Sobre la originalidad de la concepción cristiana de la existencia. Pamplona: Eunsa.

Polo, L. (2014). Epistemología, creación y divinidad. Pamplona: Eunsa.

Tomás de Aquino, Suma Teológica, I-II. 